\title{
Editorial
}

\section{La visión neoliberal fuera del alcance de El Salvador}

El plan de desarrollo sostenible ha vuelto a figurar en la agenda nacional con la designación de una comisión, cuyo objetivo es presentar al presidente Calderón la temática de dicho plan y la metodología para su formulación. De esta manera, parecería que el presidente de la república se hace eco de la demanda que, en la práctica, desde el inicio de su mandato le han hecho diversas fuerzas sociales, las cuales han criticado fuertemente a su gobierno por carecer de un plan de nación. Algunas de estas fuerzas, incluso, presentaron sus propias propuestas. Hasta este momento, el presidente de la república se mostró indiferente a todas ellas; pero el resultado electoral adverso pareciera haber cambiado su posición al respecto y ahora estaría dispuesto a concertar un plan con dichas fuerzas.

Los críticos del gobierno suponen de manera errónea que éste carece de plan. Al contrario de lo que se cree comúnmente, las acciones gubernamentales de la primera parte del período estuvieron orientadas por un plan trienal (1994-1996), elaborado por el Banco Mundial, cuyo propósito era consolidar la paz. La segunda parte del mandato de Calderón ya cuenta con otro plan similar (1997-1999), cuyo objetivo general es hacer que la paz sea sostenible. Por consiguiente, los reclamos por la falta de un proydcto no tienen fundamento. Sin embargo, la mayor parte del tiempo, el gobierno actúa como si no lo hubiera, dando la impresión de no tener rumbo. Cabe preguntarse, entonces, ¿qué posibilidades reales tiene el plan gubernamental del trienio que comienza en 1997 ?

\section{La estrategia de la competitividad}

La tesis central del nuevo plan afirma que El Salvador ya no puede seguir contando con las ventajas comparativas, derivadas del bajo costo de 
su fuerza de trabajo y de sus recursos naturales para alcanzar el desarrollo económico. Una reducción mayor del salario real sería incompatible con la sostenibilidad de la paz y con una estrategia de competitividad de largo plazo. El bajo costo de la fuerza laboral no compensa la poca productividad, ya que lo que la eleva es la innovación tecnológica. Es evidente, por otro lado, que el país no cuenta con grandes recursos naturales, ni siquiera posee ya una frontera agrícola. Ante esta realidad se propone como alternativa un crecimiento sostenido, basado en la producción y la competitividad, es decir, en la alta calidad y el bajo precio de los productos. En consonancia con esta nueva perspectiva, toda la actividad productiva nacional debe organizarse de cara a la economía mundial.

La novedad del planteamiento está en el convencimiento de que la pobreza no sólo es una de las amenazas más serias que enfrenta la estrategia de la competitividad, sino en que sin contrarrestarla, mejorando sustancialmente las condiciones de vida de los salvadoreños, aquélla no tendrá el éxito esperado. El éxito de la estrategia de la competitividad no consiste sólo en un crecimiento económico por encima del 4 por ciento, en conservar la estabilidad macroeconómica alcanzada, asegurar un flujo significativo de inversión extranjera, reducir el tamaño del Estado, privatizar sus activos, sino también, y sobre todo, en cerrar la brecha que separa a ricos y pobres y permitir que estos últimos gocen también de los beneficios del desarrollo económico.

Los pobres deben ser integrados en este movimiento competitivo - porque, a menos que la pobreza sea enfrentada con eficacia, la globalización seguirá excluyendo a una gran parte de la población y erosionando su apoyo para crear una economía competitiva.

El crecimiento económico ya no sólo debe ser constante, sino que, además, debe ampliar su base con vistas a reducir la pobreza. Más aún, el crecimiento que se desea está relacionado con una mayor competencia, la mejora de la infraestructura, la inversión en recursos humanos y el acceso al conocimiento. La realidad de los pobres y su pobreza permea la estrategia de la competitividad, propuesta para el próximo trienio.

De esta manera, los pobres, cuya cantidad abrumadora y significado social no se desconocen, deben ser integrados en este movimiento competitivo porque, a menos que la pobreza sea enfrentada con eficacia, la globalización seguirá excluyendo a una gran parte de la población y erosionando su apoyo para crear una economía competitiva. Y es que el 
apoyo social masivo es clave para asegurar el éxito de la estrategia de la competitividad. No se puede, pues, avanzar a costa de la igualdad y la integración de la mayoría de la población, de forma especial la de las áreas rurales. Así, por ejemplo, la administración de los recursos naturales no mejorará sin enfrentar de manera simultánea las raíces de la pobreza rural.

De ahí que se preste una atención inusitada al sector rural, donde se presupone se concentra la mayoría de los pobres del país y el nivel más elevado de pobreza. Para disminuir ambos se propone un sector rural expansivo y dinámico. Dado que los más pobres están vinculados a la actividad agrícola, independientemente de si poseen tierras o no, se privilegiarán las actividades rurales no agrícolas que garanticen ingresos más elevados y estables.

Esta estrategia implica una fuerza laboral sana, bien educada y cualifica$\mathrm{da}$, lo cual significa a su vez que las condiciones sociales de la mayoría de la población deben mejorar de forma sustancial. Una fuerza laboral sana conlleva revertir la tendencia de los indicadores de salud, que se encuentran muy por debajo de los de la región, erradicando las enfermedades relacionadas con la pobreza, y prestar un servicio bastante más equitativo y de mucho mejor calidad que el actual. El esfuerzo en educación debe orientarse, de manera sistemática, a elevar el nivel educativo de la población hasta que la sociedad salvadoreña sea una sociedad educada, con acceso a las fuentes de información y conocimiento. 
Simultáneamente, se propone dar poder económico y civil a las comunidades para que éstas se vuelvan productivas y autosuficientes, pues ya no deben esperar que los beneficios del crecimiento las alcancen por inercia ni que la política social del gobierno compense su baja productividad. Al llevarse a cabo esta derivación de poder social, la estructura social actual, vertical y autoritaria, se transformará en otra horizontal y participativa. Todos estos cambios se orientan a facilitar que los miembros de la sociedad puedan relacionarse en términos productivos con el conocimiento, y así puedan participar en el desarrollo nacional.

Ahora bien, la ampliación de la cobertura y la elevación de la calidad de los servicios sociales básicos implican el aumento del gasto social, lo cual no es considerado un problema mayor, siempre y cuando sea sostenible, es decir, si los beneficiarios adquieren capacidad para organizarse y volverse productivos. De la misma forma, la inversión en la infraestructura de las comunidades no será sostenible si, al mismo tiempo, no crea empleo e ingresos estables. Desde esta perspectiva, el plan conffa en la capacidad de éstas para encontrar soluciones a sus problemas y generar riqueza. Si se les da la oportunidad, sabrán aprovecharla y derivarán el poder necesario para participar activamente en la toma de decisiones.

Por lo demás, el plan no tiene nada nuevo. Se trataría, por consiguiente, de articular las políticas macroeconómicas existentes con las de desarrollo social. La articulación es considerada crucial para garantizar el éxito de las primeras a mediano y largo plazo. No se puede hablar de éxito macroeconómico, de acuerdo con el plan, si al mismo tiempo la mayoría de la población queda excluida de sus beneficios. La duda que surge, entonces, es si đicha articulación es viable, dadas las realidades económico sociales del país y los recursos humanos y financieros disponibles.

\section{Una estrategia fuera del alcance del país}

No está nada claro cómo se pueden elevar los indicadores sociales en El Salvador sin revisar y modificar a fondo las políticas macroeconómicas. El Banco Mundial y el gobierno salvadoreńo se muestran muy satisfechos con los logros obtenidos en términos de la recuperación económica - con un crecimiento de entre el 6 y 7 por ciento, entre 1991 y 1995-, del fortalecimiento de las finanzas públicas, basado en la ampliación gradual de la base impositiva y en un control más estricto del gasto público, y del control de la inflación. Desde esta perspectiva, ninguno de los dos tiene razones aparentes para introducir cambios importantes, aunque reconocen que algunos ajustes son indispensables.

Ahora bien, el banco y el gobierno no desconocen que los indicadores sociales de El Salvador son los más bajos de América Latina, siendo éste uno de los países más pobres de la región. Por lo tanto, el comportamiento 
satisfactorio de los indicadores macroeconómicos no sólo no se corresponde con el de los sociales, sino que su crecimiento y dinamismo continúan siendo muy insatisfactorios. A continuación se presentan rápidamente los indicadores sociales más importantes, según los datos proporcionados por el mismo Banco Mundial.

En educación, donde se han hecho progresos considerables, sobre todo a nivel básico, área en el cual se han concentrado los esfuerzos mayores, la calidad sigue siendo baja y los niveles de repitencia y deserción elevados, sobre todo en las zonas más pobres, en particular en el campo. De todas maneras, el ministerio se apresta a dar el siguiente paso, enfatizando la educación media.

Los indicadores sociales de El Salvador son los más bajos de América Latina, siendo éste uno de los países más pobres de la región.

En salud, la situación es mucho más crítica, porque no sólo no se mejora con la rapidez necesaria, sino que no hay acuerdo sobre las prioridades de la reforma, resulta dificil encontrar modelos alternativos para prestar el servicio y no existe consenso entre los sectores público y privado sobre los cambios. El ministerio se da un plazo de diez ańos para ejecutar las reformas necesarias. Mientras tanto, prevalecen la desnutrición y las enfermedades contagiosas - enfermedades relacionadas con la pobreza-, resurgen la malaria y el dengue, el SIDA se expande, las madres y sus hijos sufren las consecuencias de condiciones de salud deficientes, las causas más frecuentes de la muerte de los niños son la diarrea, las infecciones respiratorias agudas y el bajo peso al nacer, el 20 por ciento de los niños está desnutrido, en las áreas urbanas prevalecen las enfermedades crónicas y los embarazos de las adolescentes son un problema serio, incluso la tasa de fertilidad adolescente es una de las más altas de la región. A todo eso hay que agregar que el acceso al servicio es geográficamente desigual y su calidad es administrativa y clínicamente pobre. El cuadro que presenta la salud de la nación, cuyos indicadores están muy por debajo de los de la región, es bastante sombrío.

En 1995, el salario real, tanto en el sector público como en el privado, era la mitad de lo que era hace una década. El subempleo afecta a uno de cada dos salvadoreńos. La cantidad de trabajadores en el sector informal es casi igual a la del formal. Las dos terceras partes de la fuerza laboral no está ${ }^{\circ}$ cualificada, y tiene un promedio de 4.4 años de educación. El 25 por ciento no tiene educación formal y sólo el 12 por ciento posee más de doce años de escuela.

El país conserva únicamente el 2 por ciento del bosque original y sólo el 12 por ciento de su territorio tiene cobertura forestal. La destrucción del 
bosque ha contribuido a la erosión del suelo, afectando de forma negativa el crecimiento de la productividad y limitando la capacidad de los acuíferos para absorber el agua de la lluvia. La erosión afecta a la mitad del territorio, aumentando las posibilidades de las innundaciones. La mayor parte del cultivo de granos básicos tiene lugar en pendientes, erosionando aún más el suelo. El uso inadecuado de pesticidas y las descargas industriales y municipales perjudican las cosechas y la pesca, contaminando el agua potable y agravando la incidencia de las enfermedades gastrointestinales. Cerca de la mirad de la basura del pais no es recogida. La degradación de los recursos naturales está vinculada de forma inextricable con la pobreza rural.

El plan trienal reserva sus críticas para el área del medio ambiente, en la cual El Salvàdor no habría avanzado por falta de claridad, de una estrategia comprehensiva del desarrollo rural y de la administración de los recursos naturales y del marco legal e institucional apropiado. La nueva ley del medio ambiente se encuentra entrampada en la asamblea legislativa, porque no habría acuerdo entre quienes quisieran acentuar la severidad de las penas por transgresiones ambientales y quienes adoptan una perspectiva más promocional, orientada a animar una mejor práctica administrativa y generar una mayor conciencia.

Para hacer retroceder la línea de la pobreza se necesita una ingente cantidad de dinero. Es necesario reconocer que El Salvador ha hecho esfuerzos encomiables en esta dirección, pero éstos todavía no son suficientes. Todavía no han hecho mella en la pobreza. En efecto, el gasto social ha experimentado un incremento sustancial en los últimos años, pero aún permanece por debajo del nivel alcanzado antes de la guerra. No se gasta más porque el pals carece de recursos financieros ni se ha elevado el nivel de eficiencia en la prestación de los servicios públicos porque falta personal cualificado. Ambas cosas son condiciones necesarias si, en verdad, se quiere reducir de forma importante el nivel de la pobreza.

No obstante, el plan trienal propuesto asume que esta ambiciosa meta puede alcanzarse con un crecimiento económico mayor y sostenido, apoyado en la estrategia de la competitividad. Sin embargo, el panorama económico que aguarda a El Salvador arroja serias dudas sobre esta posibilidad. El plan mismo reconoce que el mediano plazo será crítico, puesto que las altas tasas de crecimiento económico del período inmediatamente posterior a la guerra no se repetirán. Si todo sale bien, el producto interno bruto se estabilizará alrededor del 405 por ciento anual; pero si, por el contrario, se estancase alrededor del 2 ó 3 por ciento, las políticas monetarias y fiscales dejarfan de tener sentido y los indicadores sociales y de pobreza se deteriorarían aún más, debido a la disminución del ingreso per cápita y al recorte inexorable del gasto social. 
El crecimiento esperado del producto interno bruto descansa, en primer lugar, en el incremento de las exportaciones, las cuales deben expandirse y diversificarse en gran medida. Hasta ahora, lo que más exporta El Salvador son bienes maquilados. Las exportaciones no tradicionales no crecen al ritmo deseado y el café ya no ocupa el lugar central. El segundo pilar del crecimiento lo constituye el fortalecimiento de la estructura impositiva. Aunque se han introducido mejoras en la recaudación y administración de los impuestos, al reducir de manera determinante el déficit fiscal, los ingresos fiscales en El Salvador todavía son los más bajos de América Latina, debido a que las tasas impositivas son bajas, la base de contribuyentes es estrecha y la evasión elevada. Finalmente, es necesario un ahorro público y privado, mucho mayor que el actual para financiar las inversiones.

Las remesas son ambivalentes. Mientras por un lado ayudan a elevar el nivel de vida, llenar el vacío dejado por la disminución de la ayuda externa y equilibrar la balanza comercial, por el otro. Jado contribuyen a desequilibrarla al estimular la demanda de importaciones. Al mismo tiempo, aprecian la tasa de cambio, lo cual reduce la rentabilidad de la producción agrícola, así contribuye a su estancamiento. Además, no hay que olvidar que el flujo de remesas está limitado temporalmente. Es previsible que crezcan un poco más, alcanzado su punto máximo en el mediano plazo, pero a partir de ahí, en las dos décadas siguientes, comenzarán a disminuir de forma gradual. 
Un tratado de libre comercio con el norte no garantiza de forma automática el incremento de la producción nacional. El Salvador no ha aprovechado las ventajas ofrecidas por la Iniciativa para la Cuenca del Caribe por acceder libremente al mercado estadounidense; aparte de que la mayoría de los textiles y la ropa que produce está excluida de dicho programa. Tampoco ha aprovechado las preferencias arancelarias otorgadas por México desde comienzos de los ochenta. El acceso libre a un determinado mercado cuenta poco si el país beneficiado no aprovecha la ventaja. Por otro lado, el Tratado de Libre Comercio de México y Estados Unidos perjudica a El Salvador al desviar la inversión extranjera hacia aquel país.

El crecimiento económico en la magnitud y el ritmo esperados para soportar la expansión del gasto social y la inclusión de los excluidos no está garantizado. Sus fundamentos son débiles y la menor variación podría tener consecuencias inesperadas, amenazando el éxito del plan. La vulnerabilidad de la economía podría poner en peligro la estabilidad de los índices macroeconómicos, lo cual llevaría a sacrificar los indicadores sociales. En estas condiciones, la articulación no sería posible, la pobreza continuaría siendo el dato predominante y la política neoliberal se apuntaría otro fracaso en El Salvador. La magnitud del crecimiento del ingreso requerido para reducir de forma rápida y significativa la pobreza parece estar fuera del alcance de la mayoría de los países de la región.

Así lo reconoce el Banco Interamericano de Desarrollo, para el cual, la simple combinación de un crecimiento económico mayor y sostenido, más y mejores servicios básicos para satisfacer las necesidades de los pobres y la generación de redes de solidaridad, no parecen ser suficientes para desarrollar económica y socialmente un país como El Salvador. Los datos muestran de manera consistente que la pobreza es muy elástica al crecimiento económico de corto plazo y que las reformas estructurales, de las cuales tanto se enorgullecen el Banco Múndial y el gobierno salvadoreño, parecen haber aumentado dicha elasticidad.

Un tratado de libre comercio con el norte no garantiza de forma automática el incremento de la producción nacional. El Salvador no ha aprovechado las ventajas ofrecidas por la Iniciativa para la Cuenca del Caribe por acceder libremente al mercado estadounidense;

No obstante las inversiones, las reformas y los esfuerzos, los resultados de la evolución de la pobreza, en la última década, son tan decepcionantes que el Banco Interamericano de Desarrollo concluye que las políticas aplicadas 


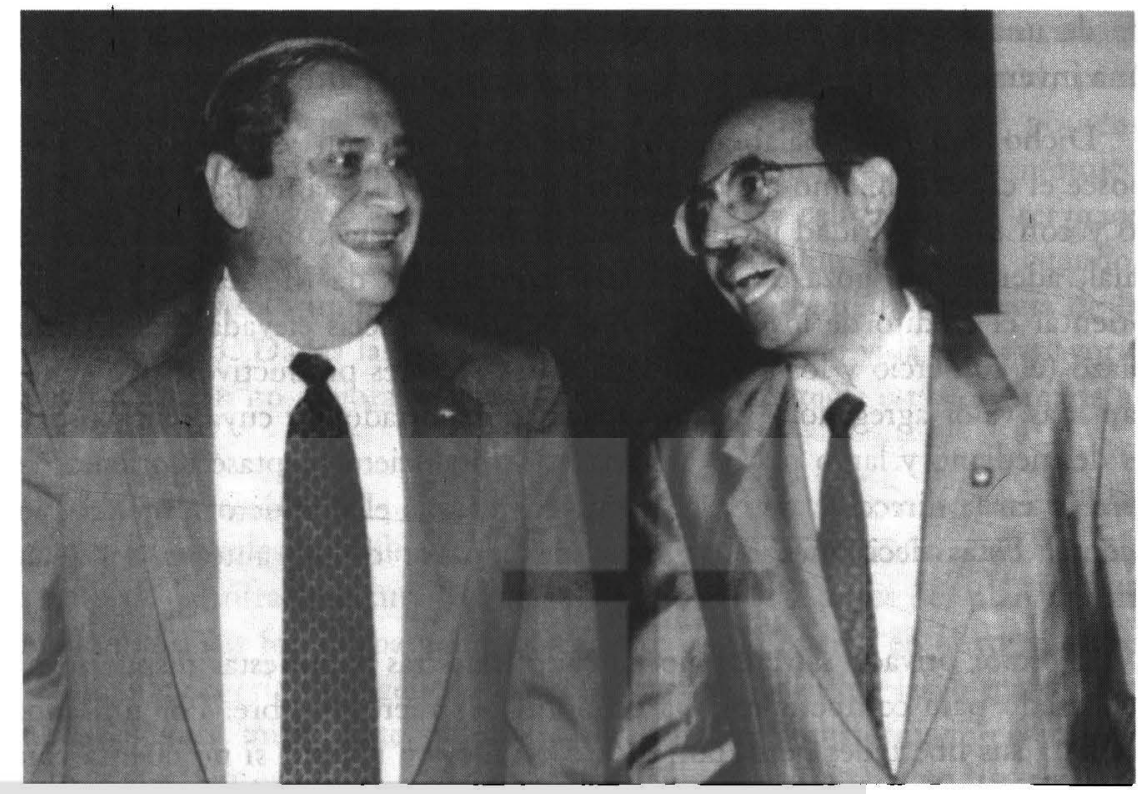

hasta ahora para erradicarla son insuficientes. Si el número de pobres no ha disminuido en América Latina, a pesar de la recuperación económica experimentada, no se ve cómo o por qué razón especial El Salvador podría ser la excepción.

\section{Los supuestos de la estrategia}

Se podría contra argumentar que, pese a que la política neoliberal no ha obtenido los resultados esperados después de una década de ajuste estructural, vale la pena continuar intentando luchar contra la pobreza y por un desarrollo sostenible con sus instrumentos. Hacer un nuevo intento en los mismos términos estaría justificado, si hubiesen razones de peso para esperar cierto éxito, pero éstas no sólo no existen, tal como lo demuestran los fracasos de una década de neoliberalismo en El Salvador y en la región, sino que además la estrategia de la competitividad, en los términos en los cuales está planteada, implica una serie de supuestos que evidencian su inconsistencia y hacen del fracaso una posibilidad real. En este sentido, el Banco Mundial muestra una ingenuidad asombrosa, aunque él mismo no descarta la posibilidad del fracaso.

El primero de esos supuestos es que el producto interno bruto no puede bajar del 4 por ciento anual, pero debe apoyarse en la producción de bienes exportables y no en los servicios y el comercio como hasta ahora. El crecimiento alcanzado por El Salvador en la década de los noventa es muy relevante, pero con todo sigue siendo inferior al de comienzos de la década de los setenta, antes de la guerra, y depende de manera casi exclusiva del comercio y los servicios. La productividad de la actividad económica depen- 
de de una inversión extranjera que tiende a orientarse hacia México o de una inversión nacional que no aparece por ninguna parte aún.

Dicho con otras palabras, depende de la decisión subjetiva de quien posee el capital. ¿Cómo atraer inversión extranjera hacia un país tan violento y con una seguridad jurídica cada vez más dudosa como El Salvador, el cual, además, no goza de las ventajas comerciales de México? ¿Cómo reorientar el crédito de los sectores que dejan ganancias elevadas en el corto plazo (el comercio y los servicios) hacia los sectores productivos, que generan más valor agregado y mayor capacidad exportadora y cuya rentabilidad es de mediano y largo plazo? Y si el sector financiero aceptase reorientar el crédito en la dirección deseada, ¿cómo lograr que el productor potencial lo acepte? Estas decisiones están fuera del alcance de los autores del plan trienal.

El sector privado salvadoreño ha dado muestras de no estar dispuesto ni preparado para competir en una economía de mercado libre. Por un lado, reclama sus libertades pero, por el otro, se niega a invertir si no cuenta con la protección del Estado o si éste no le otorga excenciones y privilegios. En la práctica, no acepta una de las reglas fundamentales del mercado libre. En el otro extremo, el gobierno salvadoreńo se encuentra atrapado entre las afirmaciones de su credo neoliberal y sus lealtades. con el capital nacional, el cual espera de él protección y privilegios. El sector privado teme a la libre competencia y el gobierno se siente naturalmente inclinado a protegerlo de sus vaivenes. Por lo tanto, en vistas a poner en marcha la estrategia de la competitividad, el sector privado debe cambiar su mentalidad, acomodando su conducta a los dictados de la competencia y el gobiernò necesita romper sus alianzas de viejo cuño con el capital. La distinción estricta entre lo privado y lo público todavia no ha sido asimilada en El Salvador como una condición indispensable de la competitividad.

El desarrollo agrícola y rural es una de las prioridades en el combate contra la pobreza. El Banco Mundial asume erróneamente que la mayor parte de la población del país es rural, pero afirma de manera acertada que la pobreza se concentra en el campo. Ahora bien, no está claro cómo recuperar la actividad económica de este sector sin alterar la política de ajuste que lo estrangula.

El segundo supuesto es que el ingreso fiscal aumentará de manera considerable para así poder financiar la expansión del gasto social. Esto es posible mejorando mucho la recaudación y la administración fiscal, pero para ello hay que ampliar e intensificar la actividad productiva. De hecho, la disminución de esta última, no obstante el crecimiento de la economía, ya está afectando de manera negativa el ingreso fiscal. Más aún, es urgente relanzar cuanto antes la producción, pues en la medida en que ésta disminuya, pondrá en serio peligro el equilibrio macroeconómico, conseguido con tanto 
sacrificio, sobre todo de las clases populares. Siempre queda, claro está, el recurso al producto de la privatización para cubrir el déficit fiscal, pero entonces el gasto social verá mermada la disponibilidad de fondos, poniendo en peligro otra de las prioridades del plan. El equilibrio macroeconómico tiende a ser conservado a costa de la expansión y la calidad de los servicios sociales para los más pobres como si de un valor absoluto se tratara, cuando, en realidad, es sólo uno de los elementos importantes de la estrategia de la competitividad. Dadas las metas del plan, si el nivel de vida de la mayoría de la población no mejora de manera radical, la estrategia está condenada al fracaso.

La privatización está pensada, desde esta perspectiva, como una de las fuentes principales para financiar la expansión del gasto social y el mejoramiento de la infraestructura del país. Más aún, los autores del plan trienal cuentan con sus fondos para crear un efecto demostrativo en el corto plazo y así acallar las críticas y generar expectativas de mediano y largo plazo. Este efecto es muy importante, porque los resultados transformadores son de largo plazo. Sin embargo, el producto de las privatizaciones podría ser desviado y destinado a conservar el precario equilibrio macroeconómico, si éste llegara a verse amenazado. De hecho, el gobierno no dispone libremente del producto de las privatizaciones. El Fondo Monetario Internacional ya lo ha obligado a comprometérse a pagar la deuda de corto plazo —originada en los desequilibrios macroeconómicos causados por la inexperiencia e irresponsabilidad de quienes asumieron la dirección de la política económica, a principios de 1996 - con el producto de la venta de la empresa de comunicaciones.

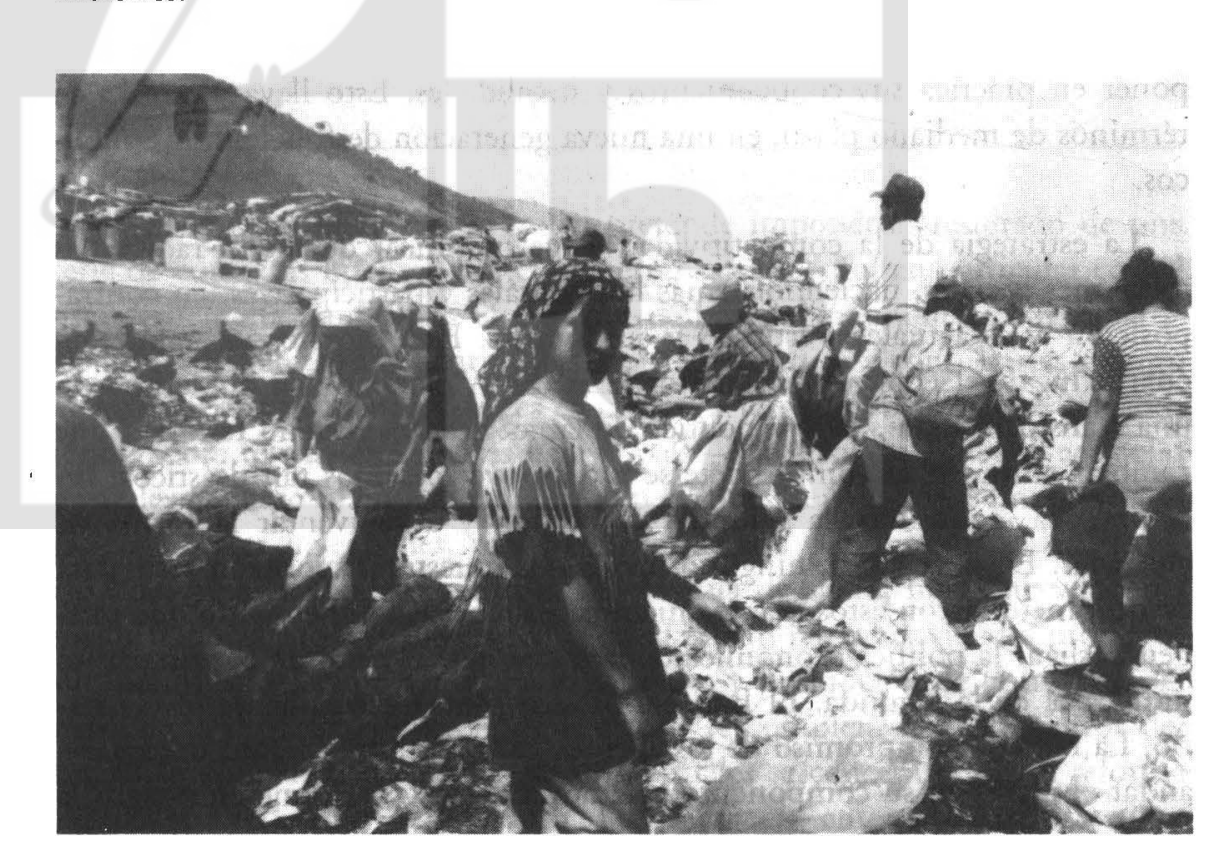


El tercer supuesto está relacionado de manera intrínseca con los dos anteriores. La ejecución exitosa de estas políticas requiere un sector público cualificado y profesional. Las reformas previstas deben ser ejecutadas con eficiencia y rapidez, lo cual no se podrá hacer sin introducir cambios profundos en un sector que hasta ahora se caracteriza por la incapacidad y la ineficiencia — su tamaño y centralización son exagerados, su estructura organizativa es intrincada, su recurso humano administrativo y financiero es pobre, su profesionalismo deja mucho que desear y su infraestructura administrativa es inadecuada. Dicho con otras palabras, El Salvador no cuenta con un sector público preparado para combatir con éxito la pobreza. Esto para no.hablar de la corrupción, de la cual, sorprendentemente, el Banco Mundial hace caso omiso al plantear su estrategia.

A esto se debe que el gobierno dé la impresión de no contar con un plan que oriente sus acciones. El problema no es la ausencia de plan, sino la incapacidad para ejecutarlo. Plan ha habido, lo que no ha habido es capacidad para ejecutarlo de manera coherente. De ahí que el gobierno pierda el rumbo con frecuencia. La modernización del Estado no se alcanza, pues, como algunos suelen repetir de forma superficial, reduciendo su tamaño. Su dimensión está supeditada a su capacidad y eficiencia. Un Estado de pequeñas dimensiones también puede ser incapaz e ineficiente.

El servidor público que el plan demanda debe estar capacitado para formular e implementar políticas públicas, sobre todo aquellas destinadas a reducir la pobreza, desarrollar los recursos humanos, proteger el medio ambiente, levantar la infraestructura fisica y administrar el sistema legal y normativo del país. Esta clase de funcionario no se improvisa, hay que prepararlo profesionalmente $y$, una vez formado, abrirle espacio para que pueda poner en práctica sus conocimientos y habilidades. Esto lleva a pensar en términos de mediano plazo, en una nueva generaciọ́n de funcionarios públicos.

La estrategia de la competitividad exige modificar de modo radical las relaciones sociales, haciéndolas más horizontales y participativas, en contraposición a las actuales, verticales y autoritarias. Este cambio presupone, en cuarto lugar, el compromiso tanto de ARENA como de su gobierno con una transformación social y política de largo alcance. Mucho tendrían que cambiar ambos para comprometerse a promover cambios tan drásticos. En la práctica, equivaldría a refundar el partido y a reinventar la forma de gobernar. En la práctica, ninguno de los dos muestra disposición seria para comprometerse con estos planteamientos. Ambos siguen pensando que pueden desligar la política económica de la social, que el éxito de la primera no implica el de la segunda. El Banco Mundial piensa exactamente lo contrario. La falta de compromiso de los agentes nacionales encargados de echar a andar el plan con su componente más novedosa no sólo pone en peligro la 
reducción del nivel de la pobreza, sino que, a mediano plazo, amenaza también los logros macroeconómicos ya logrados.

Por eso, el Banco Mundial habla de una visión del desarrollo sostenible y del país e insiste mucho en que ésta debe ser compartida, pues de ello depende el éxito del plan. Da por supuesto que el gobierno ya la ha asumido; sólo faltaría hacer partícipe a la sociedad. De hecho, el gobierno, a excepción de algunos altos funcionarios, lo único que ha hecho es integrar algunos elementos de la visión del banco en su discurso, pero está lejos de compartir con él el planteamiento integral propuesto para superar la pobreza. En realidad, no se puede esperar mucho de este gobierno cuando ni siquiera tiene claridad sobre el alcance de la competencia en la actividad económica.

\section{La visión neoliberal}

Aquí es donde se evidencia la diferencia entre el planteamiento del Banco Mundial y la postura del gobierno. La insistencia de aquél en su visión y el énfasis en que ésta sea compartida universalmente, empezando por los encargados de implementarla, revela hasta qué punto dicha visión es una imposición. Afirmar, por lo tanto, que el Banco Mundial mantiene intervenido el país o que las decisiones económicas y sociales trascendentales no se toman en El Salvador no es retórica.

El consenso social que busca el Banco Mundial para desarrollar su visión es, en realidad, ganancia de tiempo para continuar con su política neoliberal

La visión que el Banco Mundial pretende imponer es resultado de una serie de consultas intensas con el gobierno salvadoreño, en particular con el presidente de la república y el ministro de hacienda, aunque también participaron otros altos funcionarios. Se apoya en estudios y consultorías a cargo de los expertos del banco, a veces en colaboración con profesionales salvadoreños, sobre temas importantes para el país - desarrollo y finanzas agrícolas y rurales de largo plazo, género, ley de pensiones, ley de inversiones, estrategia para atraer inversiones, turismo, información por Internet, administración de crisis financieras, reforma del sistema de salud, modernización del sector público, flujo de remesas y su canalización hacia actividades productivas, administración de los recursos naturales y promoción de la imagen del pals. Estos programas del Banco Mundial se complementan con otros del Banco Interamericano de Desarrollo, los cuales se concentran en la reforma del sistema judicial y de la asamblea legislativa -entendidas ambas como 
parte de la modernización del sector público-, el fortalecimiento institucional y legal para proteger el medio ambiente, y la privatización.

El Banco Mundial se presenta como una institución dedicada al conocimiento, cuya función primordial consiste en poner a El Salvador en contacto con las fuentes de la información y del saber. Sin embargo, las recomendaciones de los estudios y las consultorías van acompañadas de la promesa de financiamiento, si aquéllas son aceptadas por el gobierno salvadoreńo. La precariedad de ideas y recursos humanos y financieros hace que éste tienda de modo invariable a aceptar tales recomendaciones, pero eso no significa compartir la visión que el Banco Mundial tiene de El Salvador. Tal vez la receptividad del gobierno salvadoreño, más motivada por la indigencia que por el convencimiento, lleve a que aquél piense que la identificación con sus intereses y metas' sea total. Quizás por eso el banco se sienta autorizado para hablar por el gobierno salvadoreño,e interpretar sus ideas y deseos. A veces parece que el Banco Mundial se acomoda a las necesidades o los criterios del gobierno salvadoreńo; pero a veces parece que el gobierno asume la visión de aquél. En realidad, el banco es el que imponę.

No obstante, el Banco Mundial aspira a que la sóciedad en su conjunto se apropie y haga suya la visión que posee sobre el futuro de El Salvador. De ahí que busque un consenso social amplio, cuyo punto de partida es la promesa de que los frutos obtenidos serán compartidos más equitativamente de lo que lo hań sido hasta ahora. La promesa será respaldada con algunos éxitos tempranos, que demuestren su posibilidad y veracidad. Esto es muy importante, porque los elementos claves del planteamiento del Banco Mundial —educación, salud, infraestructura y reformas sociales - son de largo plazo y su concretización depende de factores sumamente críticos - como la 'estabilidad macroeconómica y el incremento de la productividad y del ahorro.

En su afán por creaŕ ese consenso social tan necesario, el Banco Mundial se aproximó a las organizaciones no gubernamentales salvadoreñas, para pedir una evaluación del plan ejecutado en los tres últimos años e ideas para el nuevo. Aparentemente estaba interesado en dialogar y escuchar críticas, pero casi al mismo tiempo lanzó su nueva estrategia de la competitividad para El Salvador, en Washington. Extraña manera de buscar construir un consenso que se reconoce como fundamental, en un terreno minado por desconfianzas históricas. Al constatar que el Banco Mundial no estaba dispuesto a discutir de forma abierta su estrategia para El Salvador, sino que lo único que buscaba era poder afirmar que sostenía un diálogo permanente con las organizaciones sociales, algunas se retiraron -la UCA entre ellas.

El consenso social que busca el Banco Mundial para desarrollar su visión es, en realidad, ganancia de tiempo para continuar con su política neoliberal a cambio de distribuir de una forma más equitativa sus resultados, en un 


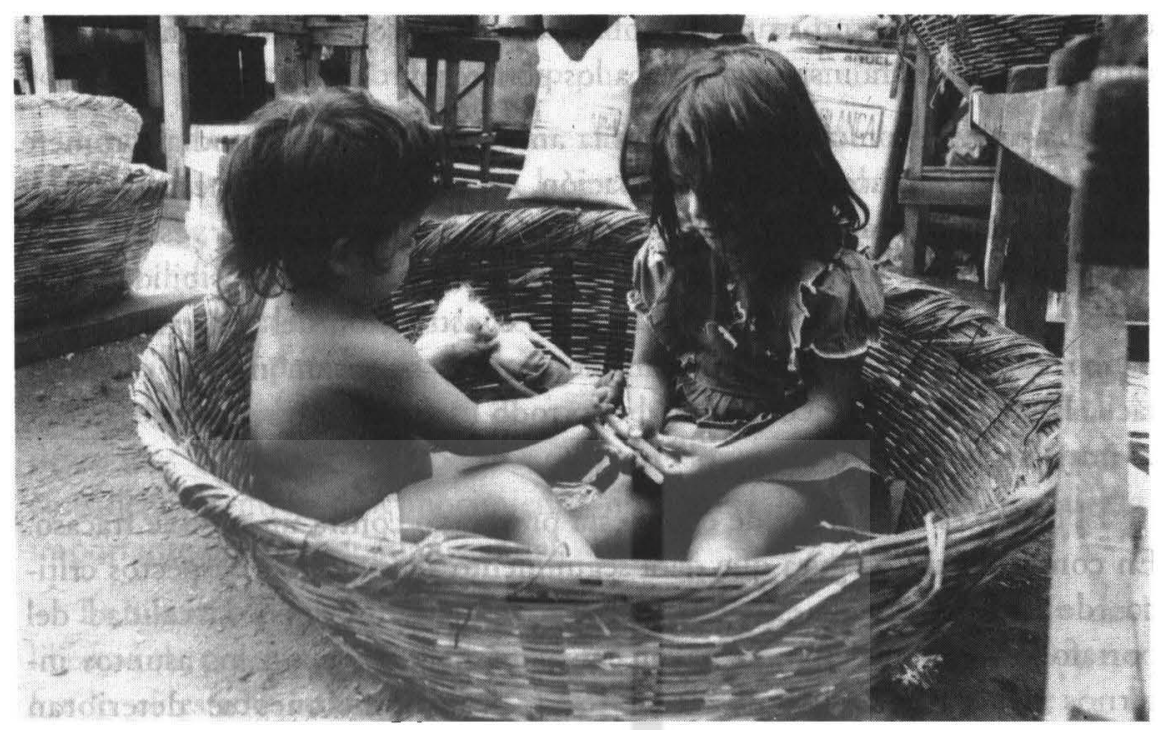

futuro próximo. En este sentido, el banco estarla solicitando a los pobres más tiempo para demostrar las bondades de su visión, a cambio de prestarles más y mejores servicios. Aceptar la propuesta del Banco Mundial supone, implícitamente, reconocer que el modelo tiene potencial para conducir al país hacia el desarrollo sostenible, lo cual es muy cuestionable, incluso para el mismo Banco Interamericano de Desarrollo.

Hasta hace muy poco tiempo, se prometió a los pobres que los beneficios del desarrollo los alcanzarían cuando sobre abundase la riqueza. Esta llegaría a un nivel tal que no podría ser contenida más y comenzaría a derramarse de manera incontenible, esparciendo sus beneficios (la tesis del rebalse). En ese entonces, se les pidieron sacrificios y paciencia. En efecto, la riqueza creció, pero en lugar de desparramarse, distribuyendo sus beneficios, se concentró aún más. La riqueza no ha faltado. Ahora hay más riqueza que antes, pero ésta está mucho más concentrada. Por lo tanto, el Banco Mundial equivoca la perspectiva cuando pide a los pobres no seguir aguardando el efecto del desbordamiento, como si ellos hubiesen propuesto esta solución o pidiesen vivir de la asistencia pública. Los pobres quieren trabajar y producir, posibilidades que les son negadas por el desempleo; así como también reclaman salud y educación al Estado, que está obligado a proporcionárselas.

Si los pobres no participan activamente en la búsqueda de soluciones a sus problemas es porque esta posibilidad les ha sido negada secularmente y cuando han intentado apropiársela, han sido reprimidos de forma salvaje. La transición política de postguerra, aunque abrió ciertos espacios, no parece estar interesada en promover aperturas de largo alcance -al menos no con la amplitud con la que el Banco Mundial tiene en mente. Por consiguiente, el problema no se encuentra del lado de los pobres, sino de quienes 
detentan el poder; no es a los pobres a quienes el Banco Mundial debe dirigirse en primera instancia, sino a los poderosos.

Una nueva promesa reemplaza a la antigua. El Banco Mundial promete empleo, salud, educación y participación, en una palabra, bienestar general y democracia participativa. A diferencia de la promesa anterior, ésta es más concreta y forma parte de un plan global, pero sus escasas posibilidades de éxito le restan credibilidad. De ahí que la construcción del consenso que el banco considera indispensable para concretizar su visión no sea obvio ni fácil. La visión del Banco Mundial con todo lo atractiva que pueda parecer, es muy frágil.

El banco es consciente de ello y está prevenido contra un posible fracaso. En consecuencia, asegura que dará seguimiento riguroso a los aspectos críticos de dicha visión —en particular, los ingresos fiscales y la calidad del portafolio-, lo cual significará una mayor intervención en los asuntos internos del país, y si a pesar de todo, sus condiciones se deterioran amenazadoramente -es decir, si la visión no es compartida o el nivel de vida de la mayoría de la población no mejora-, detendría de inmediato algunos proyectos, reduciría de manera drástica el financiamiento y tomaría distancia del gobierno salvadoreño, pues no desea ser vinculado a un fracaso que no está dispuesto a compartir. En el fracaso no habría reciprocidad, sino que toda la responsabilidad recaería sobre el gobierno y la sociedad salvadoreńos, olvidando el Banco Mundial su responsabilidad en cuanto autor de la visión y de su imposición.

Al constatar que el Banco Mundial no estaba dispuesto a discutir de forma abierta su estrategia para El Salvador, sino que lo único que buscaba era poder afirmar que sostenía un diálogo permanente con las organizaciones sociales, algunas se retiraron - la UCA entre ellas.

A la luz de este análisis, el papel de la Comisión de Desarrollo, nombrada por el presidente de la república y encargada de presentarle una propuesta con los temas y la metodología para elaborar un plan nacional, es muy limitado. El gobierno no necesita de ningún plan, puesto que ya cuenta con el del Banco Mundial, pero sí le urge contar con el consenso amplio de la sociedad que dicho plan exige. Por otro lado, es prácticamente imposible que el gobierno esté dispuesto a cuestionar la visión del Banco Mundial y sus implicaciones, arriesgando perder varios centenares de millones de dólares, sólo para satisfacer la demanda de las fuerzas sociales del pals, que desde hace más de dos años le reclaman dirección. Dadas estas circunstancias, la 
Comisión de Desarrollo parece más bien estar llamada a generar el consenso social que ni el gobierno ni el banco pueden crear por sí mismos.

Construir consenso en este contexto implica aceptar la visión del Banco Mundial para El Salvador. Dada la incapacidad del gobierno para elaborar una estrategia de desarrollo sostenible, las ideas y el dinero de otros deben ser bienvenidos; pero es muy cuestionable que lo que debiera ser ayuda se convierta en una imposición, que además dispone a su arbitrio de la vida de una nación. Es paradójico que un gobierno que tanto se enorgullece de su nacionalismo tolere un nivel de intervención tal que haya entregado las decisiones económicas y sociales a instituciones foráneas. El que éstas se consideren centros de conocimiento no atenúa la entrega de un aspecto importante de la soberanía nacional.

La Comisión de Desarrollo, llevada de un sano nacionalismo y de la libertad de pensamiento que la debiera caracterizar, bien podría replantear a fondo el estado económico y social del país, independientemente de los compromisos ya adquiridos por el gobierno. Esto podría permitir discutir de forma abierta y amplia las políticas planteadas por los bancos multilaterales así como también las otras propuestas de desarrollo, presentadas en su oportunidad por las fuerzas sociales salvadoreñas. Quizás asi se pueda llegar a construir un consenso social básico sobre el cual echar a andar un plan de desarrollo sostenible. 